\title{
Validation and reliability of the Turkish version of the inflammatory bowel disease questionnaire for ulcerative colitis and Crohn's disease
}

\author{
Haluk Tarık Kani ${ }^{1}$ (D) ilkay Ergenç ${ }^{2}$ (D), Hüseyin Arıkan ${ }^{3}$ (D), Zeynep Komesli ${ }^{4}$ (D) Berfin Seyrek ${ }^{5}$ (D), Coşkun Özer Demirtaş ${ }^{1}$ (D), \\ Yeşim Özen Alahdab ${ }^{1}$ (D), Nese Imeryüz ${ }^{6}$ (D), Özlen Atuğ ${ }^{1}$ (D) \\ 'Department of Gastroenterology, Marmara University School of Medicine, İstanbul, Turkey \\ ${ }^{2}$ Department of Internal Medicine, Marmara University School of Medicine, İstanbul, Turkey \\ ${ }^{3}$ Department of Intensive Care, Marmara University School of Medicine, İstanbul, Turkey \\ ${ }^{4}$ Department of Internal Medicine, Koc University Hospital, İstanbul, Turkey \\ ${ }^{5}$ Marmara University School of Medicine, Istanbul, Turkey \\ ${ }^{6}$ Private Practice, Istanbul, Turkey
}

Cite this article as: Kani HT, Ergenç l, Arıkan $\mathrm{H}$, et al. Validation and reliability of the Turkish version of the inflammatory bowel disease questionnaire for ulcerative colitis and Crohn's disease. Turk J Gastroenterol 2020; 31(8): 566-72.

\begin{abstract}
Background/Aims: Inflammatory bowel diseases (IBD) impair patients' quality of life (QoL). The IBD Questionnaire (IBDQ) is created to measure the health related Q $L L$ specific for IBD. We planned to investigate the validation and reliability of the Turkish translation of IBDQ.

Materials and Methods: Patients filled self-report questionnaires (Turkish IBDQ [TrIBDQ] and 36-Item Short Form Health Survey [SF36]) themselves under a physician's supervision, and they were free to ask questions about the questionnaires. The participants then filled the same questionnaires after at least two weeks. Construct validity, discriminant ability, reliability, and susceptibility to change were analyzed separately for the patients with IBD. Intra-class correlation coefficient was used to assess test-retest reliability. Cronbach's alpha values were used to assess internal consistency.

Results: A 100 patients enrolled in the study, 53 with Crohn's disease (CD) and 47 with ulcerative colitis (UC). We found a moderate-to-high positive correlation between the TrIBDQ domains and the SF-36 dimensions. In UC and CD, TrIBDQ was able to differentiate active disease and remission. We found that Cronbach's alpha for TrIBDQ domains ranged from 0.76 to 0.94 in CD and 0.79 to 0.92 in UC. The total Cronbach's alpha for TrIBDQ was 0.96 in CD and 0.95 in UC. Sensitivity-to-change analyses of the bowel, systemic, and emotional scores showed statistically significant differences between their baseline and follow-up values.

Conclusion: TrIBDQ is a valid and reliable tool for assessing the QoL in Turkish speaking patients who have IBD. Thus, it can be used in clinical research and practice.

Keywords: Crohn's disease, inflammatory bowel disease, quality of life, ulcerative colitis
\end{abstract}

\section{INTRODUCTION}

Inflammatory bowel diseases (IBD), including Crohn's disease (CD) and ulcerative colitis (UC), are chronic, idiopathic, inflammatory diseases of the gastrointestinal tract (1). IBD has an increasing incidence and prevalence (2). Patients may need surgery owing to aggressive disease course; they may have to deal with relapses, extra-intestinal manifestations, and permanent disabilities. These outcomes reduce patients' quality of life (QoL), temporarily or perpetually $(3,4)$.

QoL is a person's subjective evaluation of valuation and satisfaction with his or her life at the current time compared with what he or she perceives as possible or ideal (5). Measuring the QoL is difficult because it is subjective and de- pends on the patient's perception, but it is important to understand the impact that the disease makes on a patient's daily life. Thus, several questionnaires have been created to measure health related QoL in various diseases and conditions. IBD Questionnaire (IBDQ) is one of them and was created to measure the health-related QoL specific for IBD (6).

Validation and reliability of the translated questionnaires are important to ensure the standardization of its results. IBDQ has been translated into several languages and studied for validation and reliability in some of those languages. In the current literature, there is no validation and reliability study about IBDQ in Turkish language, and in this study, we planned to investigate the validation and reliability of the Turkish translation of IBDQ. 


\section{MATERIALS AND METHODS}

\section{Participants}

Among the patients being followed up at our university hospital's IBD specific outpatient clinic between December 2017 and September 2018, the ones who signed the informed consent were enrolled in the study. IBD was diagnosed according to the current European Crohn's and Colitis Organization guidelines. Inclusion criteria were as follows: being over 18 years old, having been diagnosed with IBD for at least 6 months, being a native Turkish speaker, and being literate. Patients with a cognitive disorder, a stoma, or a current malignant diagnosis were excluded from the study. Written informed consent was obtained from all the participants. The study was performed according to the principles of the Declaration of Helsinki and in accordance with the Medical Research Involving Human Subjects Act and was approved by the local ethics committee (Approval Date: 06.10.2017, Approval Number: 09.2017.606).

\section{Assessment}

Turkish IBDQ (TrIBDQ) consists of a total of 32 questions and has 4 sub-domains: bowel symptoms (10 questions), systemic symptoms (5 questions), emotional function (12 questions), and social function ( 5 questions) (6). The patients rated IBD-related issues with a 7-point Likert scale based on the severity of the issue in question. A rating of 1 means highest level of severity, whereas a 7 means no issue. The questionnaire inquires the patients' QoL in the past 2 weeks. The total score was between 32 and 224, where a higher score showed a better QoL. This questionnaire could be filled either by the patients themselves or with the help of an interviewer. The original IBDQ was translated into Turkish by the questionnaire provider using a rigorous methodology (7) (Figure 1). The translation process involved the collaboration between the instrument's developer and a skilled translation team in the target country, which was headed by a consultant with knowledge of and experience in the field of patient-reported outcomes, as

\section{MAIN POINTS}

A moderate-to-high positive correlation was found between the TrIBDQ domains and the SF-36 dimensions.

- The TrIBDQ could also discriminate between groups clearly according to disease severity

- The TrIBDQ is a valid and reliable tool for assessing the QoL in patients with IBD in Turkish, which indicates that it can be used in clinical research and practice. well as a centralized review process coordinated by the questionnaire provider.

The 36-Item Short Form Health Survey (SF-36) is a validated self-report scale that consists of multiple-choice and Likert questions. It was developed to evaluate the QoL of patients with physical diseases. It measures both negative and positive aspects of health status. The form evaluates health in 8 categories with 36 items such as physical functioning, role limitations, social functioning, mental health, vitality, pain, and general health perception. It is sensitive to differences in disability. Higher scores show better QoL, and its Turkish version's validation and reliability have been established $(8,9)$.

\section{Disease Activity}

Crohn's Disease Activity Index (CDAI) was utilized to assess CD activity among the participants (10). CDAI is composed of 8 questions, and the hematocrit level should be known. Scores below 150 indicate inactive disease and those above 150 points indicate active disease, whereas scores over 450 show severe disease.

Partial Mayo Score was utilized to determine UC disease activity (11). It includes stool frequency, rectal bleeding, and the physician global assessment. Scores range from 0 to 9 ; 0 to 2 points indicate inactive disease, whereas 3-4 points indicate mild disease activity, 5-6 points moderate disease activity, and 7-9 points severe disease activity.

\section{Procedure}

Patients who applied to our IBD out-patients clinic were asked randomly to participate in the study, and the ones who agreed to sign the informed consent were enrolled in the study. A detailed anamnesis was taken, and a complete physical examination was performed on all the patients. Sociodemographic data, disease characteristics, and disease activity results were recorded by the physician. Patients who were appropriate for the participation filled the self-report questionnaires (TrIBDQ and SF-36) themselves under a physician's supervision, and they were free to ask questions about the questionnaires. Same questionnaires were filled by the participants again after at least 2 weeks.

\section{Statistical Analysis}

Descriptive statistics were used to display patient and disease characteristics. Normality was assessed using the Kolmogorov-Smirnov test, Shapiro-Wilk test, and graphical methods. Count and percentage were used when available. The mean \pm standard deviation was used for 


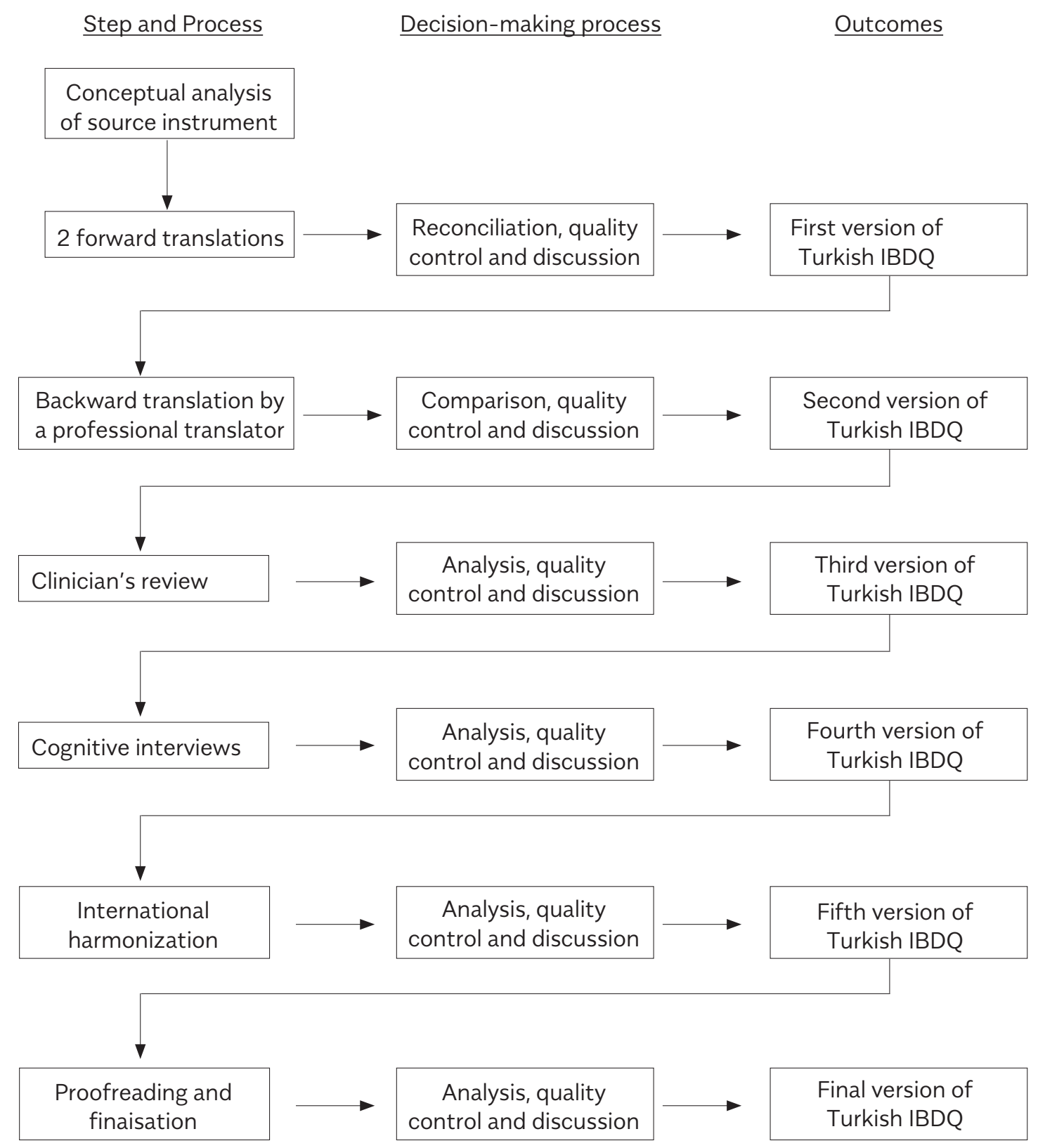

Figure 1. The methodology used for translation of IBDQ

IBDQ: Inflammatory Bowel Disease Questionnaire.

normally distributed data; the median and interquartile range (IQR) were used to display skewed data. Student's $t$ test was used when the data conformed to a normal distribution; otherwise, the Mann-Whitney U test was used.

The construct validity, discriminant ability, reliability, and susceptibility to change were analyzed separately for these
2 diagnoses to determine whether the usefulness of the questionnaire differed in patients with UC and in patients with CD. To examine construct validity, Pearson's correlation coefficients were calculated to express the relationship between indices. A t test for independent groups was used to investigate whether the TrIBDQ was able to discriminate appropriately between the 2 groups according 


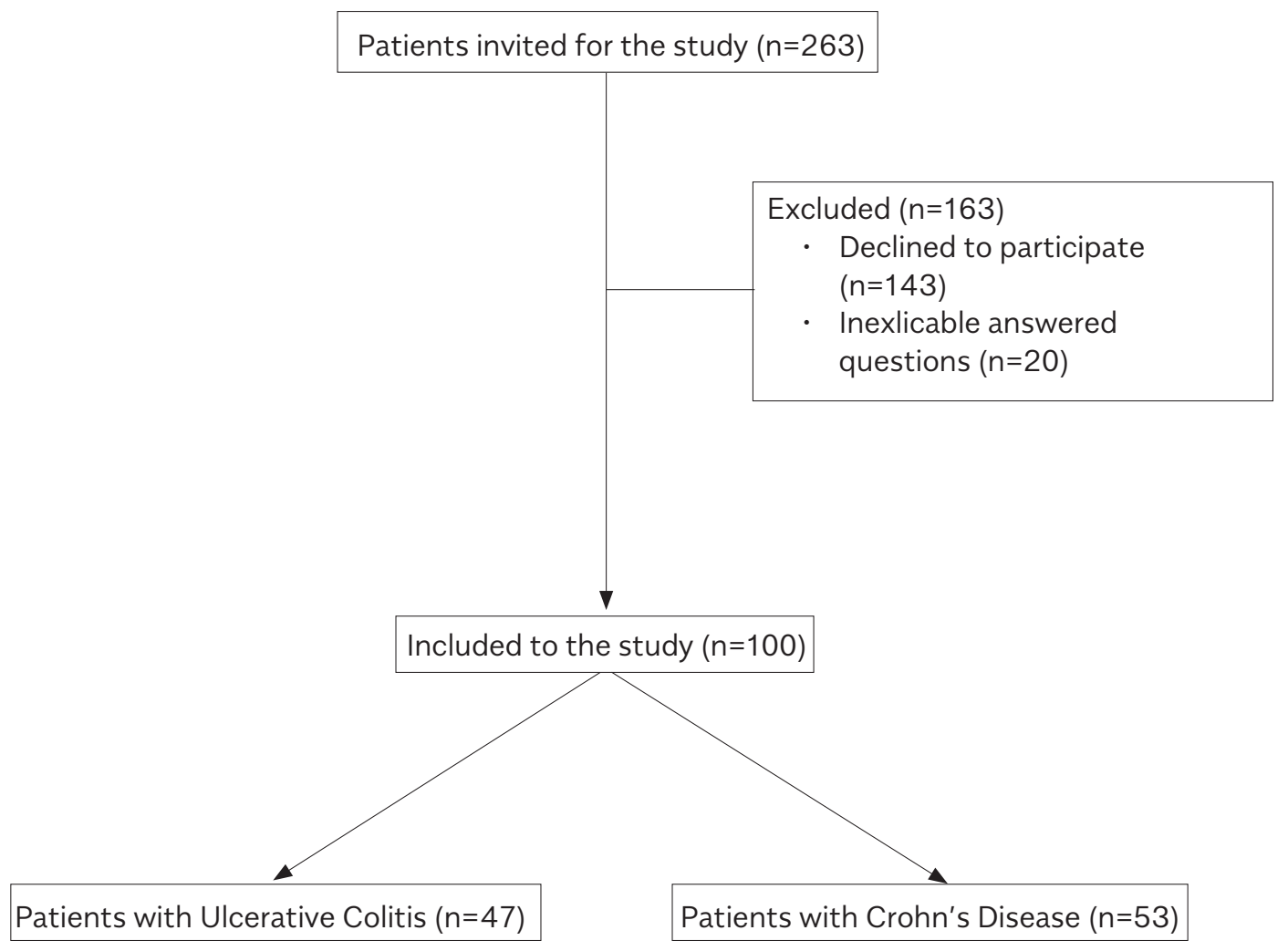

Figure 2. Flow of the study and participants included and excluded during the period.

Table 1. General characteristics of patients with $C D$ and patients with UC.

\begin{tabular}{lccc}
\hline & $\begin{array}{c}\text { All } \\
(\mathrm{n}=100)\end{array}$ & $\begin{array}{c}\mathrm{CD} \\
(\mathrm{n}=53)\end{array}$ & $\begin{array}{c}\text { UC } \\
(\mathrm{n}=47)\end{array}$ \\
\hline Male, n (\%) & $58(58)$ & $28(53)$ & $30(64)$ \\
Age, years (mean \pm SD) & $37 \pm 11$ & $37 \pm 12$ & $36 \pm 11$ \\
$\begin{array}{l}\text { Disease duration, years, } \\
\text { median (IQR) }\end{array}$ & $6(2-10)$ & $6(3-10)$ & $6(2-10)$ \\
\hline CD: Crohn's disease; UC: ulcerative colitis. & &
\end{tabular}

to disease activity and general well-being. Patients were divided into 2 categories based on whether the disease activity after retest was stable or changed. Intra-class correlation coefficient (ICC) was used to assess test-retest reliability of the TrIBDQ in those with stable disease. Cronbach's alpha values were used to assess internal consistency of TrIBDQ. A paired $t$ test was used to determine the sensitivity to change in patients who reported a change in disease activity by comparing mean IBDQ score and score change. All statistical analyses were performed using the Statistical Packages for the Social Sciences (SPSS) 23 for Windows (IBM Corp.; Armonk, NY, USA).For all analyses, statistical significance was set at 0.05 .

\section{RESULTS}

A 100 patients enrolled in the study, 53 with CD and 47 with UC (Figure 2). Patient characteristics are shown in Table 1 . The mean disease activity score was 138 for $C D$ and 2 for UC. Ninety-eight patients completed the questionnaire twice. Overall, $73(75 \%)$ of them had stable disease, 19 $(19 \%)$ of them improved, and $6(6 \%)$ of them deteriorated.

\section{Construct Validity}

Tables 2 and 3 show the Pearson's correlation coefficients assessing the relationship between TrIBDQ domains and SF-36 dimensions, disease activity, and general well-being of patients with $C D$ and patients with $U C$, respectively. We found a moderate-to-high positive correlation between the TrIBDQ domains and the SF-36 dimensions. These correlation coefficients were similar 
between patients with CD and those with UC. As for disease activity, we found a significant negative correlation between TrIBDQ domains and disease activity indices. However, this effect is more pronounced in patient group suffering from $C D$ than in the group suffering from UC.

\section{Discriminant Ability}

Participant patients were divided into 2 categories according to disease activity: in remission or active. Nineteen patients in CD group and 11 patients in UC had ac-

Table 2. Pearson's correlation coefficients between TrIBDQ domains and SF-36 dimensions, disease activity of patients with CD.

\begin{tabular}{|c|c|c|c|c|}
\hline & \multicolumn{4}{|c|}{ TrIBDQ domains in CD $(n=53)$} \\
\hline & Bowel & Systemic & Emotion & Social \\
\hline \multicolumn{5}{|l|}{ SF-36 Dimensions } \\
\hline Physical functioning & 0.63 & 0.66 & 0.62 & 0.74 \\
\hline $\begin{array}{l}\text { Role limitations because of } \\
\text { physical health problems }\end{array}$ & 0.60 & 0.59 & 0.60 & 0.75 \\
\hline Bodily pain & 0.83 & 0.76 & 0.76 & 0.75 \\
\hline General health perception & 0.71 & 0.79 & 0.78 & 0.74 \\
\hline Vitality & 0.64 & 0.79 & 0.74 & 0.70 \\
\hline Social functioning & 0.70 & 0.68 & 0.61 & 0.70 \\
\hline $\begin{array}{l}\text { Role limitations because of } \\
\text { emotional problems }\end{array}$ & 0.60 & 0.49 & 0.62 & 0.59 \\
\hline Mental health & 0.71 & 0.84 & 0.69 & 0.70 \\
\hline Disease Activity* & -0.69 & -0.65 & -0.69 & -0.72 \\
\hline \multicolumn{5}{|c|}{$\begin{array}{l}\text { *: CDAI. } \\
\text { TrIBDQ: Turkish Inflammatory Bowel Disease Questionnaire; CD: Crohn's } \\
\text { disease; SF-36: 36-Item Short Form Health Survey; CDAI: Crohn's Disease } \\
\text { Activity Index. }\end{array}$} \\
\hline
\end{tabular}

tive disease. The discriminant ability of TrIBDQ according to disease activity indices is shown in Table 4. Although TrIBDQ was able to differentiate between active disease and remission in both patient groups, the discriminant ability of TrIBDQ was more significant in the patient group with $C D$ than in the group with UC.

\section{Reliability}

According to disease activity indices, 72 patients remained stable during the test-retest period. The reliability of TrIB-

Table 3. Pearson's correlation coefficients between TrIBDQ domains and SF-36 dimensions, disease activity of patients with UC.

TrIBDQ Domains in UC $(n=47)$
Bowel Systemic Emotion Social

\section{SF-36 Dimensions}

\begin{tabular}{|c|c|c|c|c|}
\hline Physical functioning & 0.53 & 0.64 & 0.53 & 0.61 \\
\hline $\begin{array}{l}\text { Role limitations be cause of } \\
\text { physical health problems }\end{array}$ & 0.56 & 0.61 & 0.48 & 0.71 \\
\hline Bodily pain & 0.71 & 0.64 & 0.60 & 0.69 \\
\hline General health perception & 0.50 & 0.66 & 0.53 & 0.54 \\
\hline Vitality & 0.54 & 0.73 & 0.71 & 0.55 \\
\hline Social functioning & 0.49 & 0.63 & 0.50 & 0.71 \\
\hline $\begin{array}{l}\text { Role limitations } \\
\text { because of emotional } \\
\text { problems }\end{array}$ & 0.45 & 0.53 & 0.51 & 0.59 \\
\hline Mental health & 0.51 & 0.73 & 0.61 & 0.54 \\
\hline Disease Activity* & -0.45 & -0.26 & -0.28 & -0.35 \\
\hline
\end{tabular}

*: Partial Mayo Score.

TrIBDQ: Turkish Inflammatory Bowel Disease Questionnaire; UC: ulcerative colitis, SF-36: 36-Item Short Form Health Survey,

Table 4. Discriminant ability of TrIBDQ according to disease activity indices.

\begin{tabular}{|c|c|c|c|c|c|c|}
\hline \multirow[b]{2}{*}{ TrIBDQ Domains mean (SD) } & \multirow{2}{*}{$\frac{C D(n=53)^{*}}{\text { Remission } n=33}$} & \multicolumn{5}{|c|}{ UC $(n=47)^{\dagger}$} \\
\hline & & Active $n=19$ & $\mathrm{p}^{\ddagger}$ & Remission $\mathrm{n}=36$ & Active $n=11$ & $\mathrm{p}^{\ddagger}$ \\
\hline Bowel symptoms & $5.5(0.6)$ & $3.7(1.2)$ & $<0.001$ & $4.8(1.1)$ & $3.8(1.1)$ & 0.02 \\
\hline Systemic symptoms & $4.9(1.1)$ & $3.1(1.1)$ & $<0.001$ & $4.6(1.1)$ & $3.8(1.2)$ & 0.048 \\
\hline Emotional function & $4.9(0.9)$ & $3.1(1.1)$ & $<0.001$ & $4.4(1.1)$ & $3.7(0.9)$ & 0.04 \\
\hline Social function & $5.6(0.9)$ & $3.6(1.8)$ & $<0.001$ & $5.3(1.2)$ & $4.1(1.3)$ & 0.02 \\
\hline
\end{tabular}

*: Disease activity assessed by CDAl; ${ }^{\dagger}$ : Disease activity assessed by Partial Mayo Score; ${ }^{\ddagger}$ : Student's t test.

TrIBDQ: Turkish Inflammatory Bowel Disease Questionnaire; CD: Crohn's disease; UC: ulcerative colitis; SD: standard deviation; CDAl: Crohn's Disease Activity Index. 
Table 5. Reliability of TrIBDQ.

\begin{tabular}{lccccccccc}
\hline & \multicolumn{4}{c}{ CD $(\mathrm{n}=35)$} & & \multicolumn{3}{c}{ UC $(\mathrm{n}=37)$} \\
\cline { 2 - 8 } TrIBDQ domains mean (SD) & Baseline & Follow-up & $\mathrm{p}^{*}$ & ICC & Baseline & Follow-up & $\mathrm{p}^{*}$ & ICC \\
\hline Bowel & $5(1.2)$ & $5.2(1.3)$ & 0.275 & 0.83 & $4.7(1.1)$ & $4.8(1.2)$ & 0.321 & 0.73 \\
Systemic & $4.5(1.5)$ & $4.9(1.5)$ & 0.051 & 0.76 & $4.5(1.2)$ & $4.6(1.3)$ & 0.550 & 0.64 \\
Emotional & $4.6(1.5)$ & $4.6(1.6)$ & 0.905 & 0.89 & $4.2(1.1)$ & $4.4(1.4)$ & 0.270 & 0.80 \\
Social & $5.1(1.7)$ & $5.2(1.6)$ & 0.399 & 0.90 & $5.2(1.3)$ & $5.3(1.4)$ & 0.437 & 0.85 \\
\hline
\end{tabular}

*: Paired samples t test.

TrIBDQ: Turkish Inflammatory Bowel Disease Questionnaire; CD: Crohn's disease; UC: ulcerative colitis; SD: standard deviation; ICC: intra-class correlation coefficient.

Table 6. Sensitivity to Change of the TrIBDQ.

\begin{tabular}{lcccc}
\hline $\begin{array}{l}\text { TrlBDQ domains } \\
\text { mean (SD) }\end{array}$ & \multicolumn{4}{c}{ All deteriorated or improved patients $(\mathrm{n}=25)$} \\
\cline { 2 - 5 } Bowel & Baseline & Follow-up & Difference $(95 \% \mathrm{Cl})$ & $\mathrm{p}$ \\
Systemic & $4(1.1)$ & $4.5(1.2)$ & $0.5(0.19-0.82)$ & 0.003 \\
Emotional & $3.7(1)$ & $4.3(1.2)$ & $0.6(0.29-0.87)$ & 0.006 \\
Social & $3.7(1.1)$ & $4.2(1.3)$ & $0.6(0.17-0.95)$ & $<0.001$ \\
\hline
\end{tabular}

*: Paired samples t test.

TrIBDQ: Turkish Inflammatory Bowel Disease Questionnaire; SD: standard deviation; Cl: confidence interval.

DQ was assessed regarding these patients. Table 5 shows changes of TrIBDQ domains and ICCs. In the CD group, all correlation coefficients were very high except systemic symptoms domains that were still high. The UC group had high correlation coefficients but still lower than those of the $\mathrm{CD}$ group. Cronbach's alpha for TrIBDQ domains ranged from 0.76 to 0.94 in the CD group and from 0.79 to 0.92 in the UC group. The total Cronbach's alpha for TrIBDQ was 0.96 in the $C D$ group and 0.95 in the UC group.

\section{Sensitivity to Change}

Of all the patients, 6 deteriorated ( $2 \mathrm{CD}, 4 \cup C)$ and $19 \mathrm{im}$ proved ( $13 \mathrm{CD}, 6 \cup \mathrm{C})$. To increase the sample size, scores of the deteriorated patients were reversed but because of the small sample size of this sub-group of patients, individual analyses for $C D$ and $U C$ could not be made. Overall sensitivity-to-change analysis of TrIBDQ is shown in Table 6. Bowel, systemic, and emotional scores were found to be statistically different from baseline to follow-up.

\section{DISCUSSION}

IBD affects the QoL of patients, and it is important to measure QoL to understand the change over time with therapy and other intervention in research and clinical practice. The original IBDQ has been shown to be a valid and reliable tool in the English language. However, the Turkish version of the IBDQ had not been validated until our work. In this work, construct validity, discriminant ability, reliability, and sensitivity to change of the instrument were tested and found to be acceptable and similar in both UC and CD.

Validity was investigated by measuring the correlations between TrIBDQ, SF-36, and disease activity. We found a moderate-to-high positive correlation between the TrIBDQ domains and the SF-36 dimensions. These correlation coefficients were similar between patients with $C D$ and those with UC. As for disease activity, we found a significant negative correlation between TrIBDQ domains and disease activity indices. However, this effect is more pronounced in the patient group suffering from CD than in the group who have UC. These results show a satisfactory validation in both patients with $C D$ and patients with UC.

The internal consistency coefficients were high and satisfactory in our study, and it shows a great internal con- 
sistency for UC and CD (Table 5). The Chronbach's alpha values were high not only for the TrIBDQ overall but also for each of the 4 original dimensions of it. In the CD group, all correlation coefficients were very high except the systemic symptoms domains, which were still high. The group with UC had high correlation coefficients but lower than those of the group with CD. TrIBDQ was successful considering reliability, and similar results were seen in previous studies $(12,13)$.

In our study, the TrIBDQ could also discriminate between groups clearly according to disease severity (Table 4). All TrIBDQ sub-scores were significantly lower in the active disease group than in patients in remission. This result also shows a powerful discriminant ability of TrIBDQ.

There were only 6 patients with increased disease activity in follow-up, and it was insufficient to assess the sensitivity to change in the activation. We included all deteriorated and improved patients in the analyses and found statistically significant differences between the baseline and follow-up scores for bowel, systemic, and emotional scores.

Limitation of our study was the small sample size in the sensitivity-to-change group in the activation phase. Nevertheless, the sensitivity was seen as satisfactory in our analyses when we included all the patients with altered disease scores.

Patients filled the questionnaire by self-report; however, a physician was always available to answer patients' questions to decrease the number of missing data and unanswered questions. Self-report and interview-based methods provided similar results, and no significant difference was seen in the results (14).

In conclusion, the TrIBDQ is a valid and reliable tool for assessing the QoL in patients with IBD in Turkish, which indicates that it can be used in clinical research and practice.

Ethics Committee Approval: Ethics committee approval was received for this study from the Ethics Committee of Marmara University (Approval Date: 06.10.2017, Approval Number: 09.2017.606)

Informed Consent: Written informed consent was obtained from the patients who participated in this study.

Peer-review: Externally peer-reviewed.
Author Contributions: Concept - H.T.K., I.E., H.A., Ö.A.; Design H.T.K., I.E., H.A., Ö.A.; Supervision - N.I., Ö.A.; Resource - I.E., B.S.; Materials - I.E., B.S.; Data Collection and/or Processing - I.E., B.S., C.Ö.D.; Analysis and/or Interpretation - H.A.; Literature Search - H.T.K., I.E.; Writing - H.T.K., H.A., Z.K.; Critical Reviews - Y.O.A., N.I., Ö.A.

Acknowledgements: Use of the Inflammatory Bowel Disease Questionnaire, authored by Jan Irvine et al. (1999), was made under license from McMaster University, Hamilton, Canada.

Conflict of Interest: The authors have no conflict of interest to declare.

Financial Disclosure: The authors declared that this study has received no financial support.

\section{REFERENCES}

1. Atug $O$, Kani HT, Banzragch $M$, Imeryuz $N$, Akin $H$. Incidence rate of anemia in inflammatory bowel diseases. Turk J Gastroenterol 2016; 27: 143-8. [Crossref]

2. Molodecky NA, Soon IS, Rabi DM, et al. Increasing incidence and prevalence of the inflammatory bowel diseases with time, based on systematic review. Gastroenterology 2012; 142: 46-54.e42; quiz e30. [Crossref]

3. Graff $L A$, Walker JR, Lix $L$, et al. The relationship of inflammatory bowel disease type and activity to psychological functioning and quality of life. Clin Gastroenterol Hepatol 2006; 4: 1491-501. [Crossref]

4. Fiorino G, Allocca M, Chaparro M, et al. 'Quality of Care' Standards in Inflammatory Bowel Disease: A Systematic Review. J Crohn's Colitis 2018: 13: 127-37. [Crossref]

5. Leong RW, Lee YT, Ching JY, Sung JJ. Quality of life in Chinese patients with inflammatory bowel disease: validation of the Chinese translation of the Inflammatory Bowel Disease Questionnaire. Aliment Pharmacol Ther 2003; 17: 711-8. [Crossref]

6. Guyatt G, Mitchell A, Irvine EJ, et al. A new measure of health status for clinical trials in inflammatory bowel disease. Gastroenterology 1989; 96: 804-10. [Crossref]

7. Acquadro C, Conway K, Christelle G, I M. Linguistic Validation Manual for Patient-Reported Outcomes (PRO) Instruments. 2004.

8. Ware JE, Jr., Sherbourne CD. The MOS 36-item short-form health survey (SF-36). I. Conceptual framework and item selection. Med Care 1992; 30: 473-83. [Crossref]

9. Koçyiğit $H$, Aydemir Ö, Fişek G, Ölmez N, Memiş A. [Validity and reliability of Turkish version of short form 36 (SF-36)]. Ilaç ve tedavi dergisi 1999; 12: 102-6.

10. van Hees $P A$, van Elteren $P H$, van Lier HJ, van Tongeren JH. An index of inflammatory activity in patients with Crohn's disease. Gut 1980; 21: 279-86. [Crossref]

11. Schroeder KW, Tremaine WJ, Ilstrup DM. Coated oral 5-aminosalicylic acid therapy for mildly to moderately active ulcerative colitis. A randomized study. N Engl J Med 1987; 317: 1625-9. [Crossref] 12. Lopez-Vivancos J, Casellas F, Badia X, Vilaseca J, Malagelada JR. Validation of the spanish version of the inflammatory bowel disease questionnaire on ulcerative colitis and Crohn's disease. Digestion 1999; 60: 274-80. [Crossref]

13. Ren WH, Lai M, Chen Y, Irvine EJ, Zhou YX. Validation of the mainland Chinese version of the Inflammatory Bowel Disease Questionnaire (IBDQ) for ulcerative colitis and Crohn's disease. Inflamm Bowel Dis 2007; 13: 903-10. [Crossref]

14. Irvine EJ, Feagan BG, Wong CJ. Does self-administration of a quality of life index for inflammatory bowel disease change the results? J Clin Epidemiol 1996; 49: 1177-85. [Crossref] 